\title{
Effects of Mobility Programmes on University Students' Academic Performance
}

\author{
González-Baixauli, Cristóbal ${ }^{a}$; Montañés-Brunet, Elvirab ${ }^{b}$ and Pérez-Vázquez, Pedro \\ José $^{\mathrm{c}}$
}

${ }^{\mathrm{a}}$ Faculty of Economics, University of Valencia, Spain, ${ }^{\mathrm{b}}$ IULMA, University of Valencia, Spain, ${ }^{\mathrm{c}} \mathrm{MC} 2$, University of Valencia, Spain,

\begin{abstract}
The number of students participating in mobility programmes has increased enormously over the years. The reasons are diverse and may range from personal growth to better employability prospects, together with improvement in foreign language skills and intercultural awareness. Mobility programmes receive generous funding from the European Commission, therefore their outcomes should be measured and evaluated. This paper focuses on a specific one: the academic effects of mobility programmes. We analyse whether there is an improvement in the academic performance of the students who participate in mobility programmes and, if this is the case, whether it is sustained over time. We use a broad dataset of students from the Faculty of Economics of the University of Valencia over a period of thirteen academic years. The results indicate that students participating in a mobility programme experiment a marked improvement in their scores at the host university, but this upgrading: a) is not homogeneous across the mobility programs or geographical areas considered; and b) partially vanishes off when the students come back to their home university.
\end{abstract}

Keywords: Academic performance; mobility programmes; international student mobility; grade point average; Economics degree; Business Administration degree. 


\section{Introduction}

Student mobility programmes in tertiary education supports the EU's strategic framework for education and training, promoting growth and equality, better job opportunities and cooperation among countries. The number of university students taking part in mobility programmes has risen dramatically over the last decades. Its benefits may range from personal growth to professional development: it enhances students' foreign language and intercultural competence, their self-confidence and their future employability prospects.

The potential benefits of a mobility programme cannot be underrated; however, to prevent students from using it as "sponsored vacations" (Juva \& Lesjak, 2011) and assess its effectiveness and usefulness, the academic performance of mobility students should be measured and evaluated; nevertheless, this specific field of research has not received much attention. Many studies analyze the effects of mobility programmes [Maiworm \& Teichler 2002; Williams 2005; Messer \& Wolter 2007; Crossman \& Clarke 2010; Wiers-Jenssen 2011; or Di Pietro 2013, amongst others], but these studies almost rely entirely on students' self-assessment of their stay abroad and their probability of employability in a foreign country without analysing the influence of the mobility experience on the students' academic performance. The aim of this paper is to fill this gap in the literature: to the knowledge of the authors, besides the work of Sanz \& Roldan (2005), Meya \& Sutheim (2014) and Pérez-Vázquez et al., (2014), this is one of the first attempts to assess the effects of the mobility stay on the students' academic performance. Specifically, we address two questions:

a) Do the students significantly improve their grades during their mobility stay? If so, which factors are behind that improvement?

b) Do the students significantly improve their grades after their mobility stay? If so, which factors are behind that improvement?

An extensive dataset of students from the degrees of Economics and Business Administration (BA) at the University of Valencia (UV) has been used, ranging from the year 2001-02 to 2013-14, a larger sample than the ones employed in the aforementioned analogous studies. ${ }^{1}$

This paper is structured as follows. After the introduction, section two describes the dataset and shows some summary statistics. The econometric analysis is carried out in section

\footnotetext{
${ }^{1}$ The authors wish to thank Dr. José Manuel Pastor (Dean of the Faculty of Economics) and Dr. Guillermo Palao (Vice Chancellor of Internationalization and Cooperation) for their involvement and assistance in obtaining the data. They also wish to thank Mr Vicent Girbés and Mrs Elena Barea for their help in the management process thereof.
} 
three. Section four closes the paper indicating the main conclusions obtained from the results found.

\section{Data set and preliminary results}

The original sample is broad in scope and time, as it covers thirteen academic years (from 2001-02 to 2013-14). The database includes anonymous information about 15,333 students. Table 1 contains part of the available information per student used in this paper, indicating original data (Panel A) and new variables created from the original database (Panel B) ${ }^{2}$.

The quantity and quality of the data sample for each student is quite heterogeneous. Since we need to measure the students' GPAs at different stages of their academic life, we have screened the data, applying several filters. The aim is to work with a sample rich enough in terms of data by individual, and homogeneous enough in terms of type of individuals to obtain sufficiently robust results. This selection procedure has led to restrict our sample to a figure of 6,387 students. Table 2 shows the main features of the sample used.

The most striking result is the difference between the average GPA for mobility and nonmobility students during their university studies. On average, there are 0.42 points of difference between their respective GPAs [6.82 vs 6.40]. However, some questions about this result can be raised, such as: To which extent this difference is statistically significant? Does it come from the fact that the best students are the ones who join academic mobility programmes? Or does the mobility period help to improve their GPA? ${ }^{3}$ These are the questions addressed in the paper.

\footnotetext{
${ }^{2}$ Some of these variables have been created from the academic record of each student $i$ (i.e., a list with all the subjects passed, plus the corresponding grade points and the dates when they were obtained). The global figure of academic records is 772,114 ; i.e. on average, the database contains around 50 academic records per student. For the sake of space, only the variables used in this paper have been included in the table.

${ }^{3}$ Notice that their GPAs' difference when they did join the UV was 0.41 points greater on average [6.88 vs 6.47], so it is practically the same than the one existent when they finish their studies at the university. In this sense, Meya \& Suntheim (2014) find that the final university grade is 0.2 grades better for those who count the grades obtained at the foreign university towards their degree in contrast to those who do not transfer any grades.
} 
Table 1: Variables used in the analysis

\section{Panel A: Original data in the sample}

\begin{tabular}{|c|c|}
\hline Notation & Description of the variable \\
\hline Gender $_{i}$ & Gender of the student $i(1:$ male; $0:$ female $)$; \\
\hline$F S_{i}\left(M S_{i}\right)$ & Level of academic studies of the student $i$ 's father (mother); \\
\hline$F E_{i}\left(M E_{i}\right)$ & Economic status of the student $i$ 's father (mother); \\
\hline Degree $_{i}$ & Degree of the student $i ;(1:$ Economics; $0: B A)$; \\
\hline Dest_Univ $_{i}$ & University of mobility destination of the student $i$ \\
\hline$G P A_{-} 0_{i}$ & Grade Point Average (GPA, hereafter) of student $i$ to access to the UV; \\
\hline \multicolumn{2}{|c|}{ Panel B: Additional variables created from original database } \\
\hline$G P A_{-} U V_{i}$ & GPA at the University of Valencia obtained by the student $i$; \\
\hline$G P A_{-} b_{i}$ & GPA obtained by the student $i$ at the UV before his/her mobility period; \\
\hline$G P A_{-} d_{i}$ & $\begin{array}{l}\text { GPA obtained by the student } i \text { at the host university during his/her mobility } \\
\text { period; }\end{array}$ \\
\hline$G P A \_a_{i}$ & GPA obtained by the student $i$ at the UV after his/her mobility period; \\
\hline$G P A_{-} U_{n i v}$ & GPA at the university obtained by the student $i ;^{4}$ \\
\hline$M o b_{i}$ & Mobility student (1: yes; 0: no). \\
\hline Geog_zone $_{i}$ & Geographical area of mobility; \\
\hline$U F_{i}\left(U M_{i}\right)$ & Unemployed father (mother) (1: yes; $0:$ no) \\
\hline
\end{tabular}

\footnotetext{
${ }^{4}$ For non-mobility students $G P A_{-} U n i v_{i}=G P A_{-} U V_{i}$ whereas for mobility students GPA_Univ i is a weighted average of $G P A_{-} U V_{i}$ and $G P A_{-} d_{i}$; i.e., a weighted average of the GPA obtained at the UV and the GPA obtained at the host university. Note also that for mobility students $G P A_{-} U V_{i}$ is just a weighted average of $G P A_{-} b_{i}$ and $G P A_{-} a_{i}$.
} 
Table 2 Basic features of the final sample (6,387 students)

\begin{tabular}{|c|c|c|c|c|c|c|c|c|}
\hline & \multicolumn{4}{|c|}{ Mobility students $(\mathrm{N}=1,333)$} & \multicolumn{4}{|c|}{ Non mobility students $(\mathrm{N}=5,054)$} \\
\hline$\%$ Women & \multicolumn{4}{|c|}{$50.41 \%$} & \multicolumn{4}{|c|}{$50.17 \%$} \\
\hline$\%$ BA degree & \multicolumn{4}{|c|}{$65.79 \%$} & \multicolumn{4}{|c|}{$52.63 \%$} \\
\hline & \multicolumn{2}{|c|}{ Business Adm. } & \multicolumn{2}{|c|}{ Economics } & \multicolumn{2}{|c|}{ Business Adm. } & \multicolumn{2}{|c|}{ Economics } \\
\hline & Females & Males & Females & Males & Females & Males & Females & Males \\
\hline \multirow{2}{*}{$\begin{array}{c}\text { Average } \\
G P A \_0\end{array}$} & 7.12 & 6.84 & 6.84 & 6.55 & 6.78 & 6.53 & 6.35 & 6.16 \\
\hline & \multicolumn{4}{|c|}{6.88} & \multicolumn{4}{|c|}{6.47} \\
\hline \multirow{2}{*}{$\begin{array}{c}\text { Average } \\
\text { GPA_Univ }_{i}\end{array}$} & 6.94 & 6.80 & 6.76 & 6.65 & 6.53 & 6.35 & 6.42 & 6.28 \\
\hline & \multicolumn{4}{|c|}{6.82} & \multicolumn{4}{|c|}{6.40} \\
\hline
\end{tabular}

\section{Factors affecting the academic performance}

Our goal is to detect whether the fact of joining an academic mobility programme has a direct effect on the student performance. To do so, we carry out a regression analysis. Specifically, the model to be estimated is specified in [Eq.1]. ${ }^{5}$

$$
\begin{aligned}
\text { GPA_Univ }_{i}= & \beta_{0}+\beta_{1} \cdot \text { GPA_0 }_{i}+\beta_{2} \cdot \text { Degree }_{i}+\beta_{3} \cdot \text { Gender }_{i}+\beta_{4} \cdot F S_{i}+\beta_{5} \cdot M S_{i}+ \\
& +\beta_{6} \cdot U F_{i}+\beta_{7} \cdot U M_{i}+\beta_{8} \cdot \text { Mob }_{i}+\varepsilon_{i}
\end{aligned}
$$

where $\varepsilon_{i}$ is an stochastic term distributed $\boldsymbol{N}\left(\mathbf{0}, \sigma_{\varepsilon}^{2}\right)$

The results obtained (see Table 3) seem to indicate that both the GPA when joining the UV and the participation in a mobility programme play a direct and leading role in the explanation of the GPA obtained by the student at the university. Thus, not surprisingly, the better the performance before entering the UV, the higher the GPA at the university; but also the fact of spending part of their university life in a host university contributes to enhance their GPA. Both variables are statistically significant at 99\%. Interestingly, it also seems that other factors such as the gender of the student and, to a lesser extent, the degree studied and the academic level of the student's mother can contribute to explain the student's GPA. This finding is in line with previous literature [see Garbanzo (2007) or Parveen \& Alam (2008)].

\footnotetext{
${ }^{5}$ Recall that the endogenous variable in Eq. 1, GPA_Univ ${ }_{i}$ for a non-mobility student is just the GPA obtained at the UV whereas that for a mobility student is a weighted average of the GPA obtained at the UV before and after the mobility period and the GPA obtained at the host university.
} 
To gain some insight on the effects of mobility on students' academic performance, Table 4 shows the averages of the students' GPA at three different stages: before (GPA_b), during $\left(G P A \_d\right)$, and after $\left(G P A \_a\right)$ their mobility period. The results indicate that women do better than men in all stages of the university years considered and BA students have a slightly better academic performance than their Economics counterparts do. More interestingly for our purposes, it can be seen that for the four groups of students considered -after a decrease in their GPA compared to the one with which they accessed the university $\left(G P A \_b<G P A \_0\right)$ - the mobility period contributes to an improvement in their academic performance $\left(G P A \_d>G P A \_b\right)$. This upgrading is especially relevant for BA students, since near 0.7 points (out of 10 ) of improvement are obtained.

Table 3: Factors affecting GPA_Univ

\begin{tabular}{cccc} 
Variable & Coefficient value & Std. Error & t value \\
\hline Intercept & $3.4874^{\mathrm{a}}$ & 0.0949 & 36.744 \\
GPA_0 & $0.4371^{\mathrm{a}}$ & 0.0127 & 34.326 \\
Degree: Economics & $0.0495^{\mathrm{c}}$ & 0.0218 & 2.274 \\
Gender: Male & $-0.0549^{\mathrm{b}}$ & 0.0213 & -2.583 \\
FS & -0.0145 & 0.0089 & -1.629 \\
$M S$ & $0.0191^{\mathrm{c}}$ & 0.0097 & 1.971 \\
UF & 0.0383 & 0.0264 & 1.449 \\
UM & -0.0238 & 0.0242 & -0.983 \\
Mob & $0.3185^{\mathrm{a}}$ & 0.0253 & 12.601
\end{tabular}

$\mathrm{R}^{2}: 0.345$

F-statistic : 220.4

Note: superscripts $a, b$ and c imply statistical significance at 99.9\%, 99\%, and 95\% levels, respectively. 
Table 4: Academic performance throughout different academic stages

\begin{tabular}{llccccc} 
& & & \multicolumn{4}{c}{ Average academic performance } \\
\cline { 5 - 7 } Degree & Gender & Students & $G P A \_0$ & $G P A \_b$ & $G P A \_d$ & $G P A_{-} a$ \\
\hline BA & All & 877 & 6.99 & 6.60 & 7.30 & 6.88 \\
& Females & 468 & 7.12 & 6.67 & 7.35 & 6.94 \\
& Males & 409 & 6.83 & 6.53 & 7.24 & 6.82 \\
\hline Economics & All & 456 & 6.68 & 6.55 & 6.96 & 6.72 \\
& Females & 204 & 6.84 & 6.62 & 7.00 & 6.82 \\
& Males & 252 & 6.55 & 6.49 & 6.93 & 6.64 \\
\hline \multicolumn{2}{c}{ Total students } & 1,333 & 6.88 & 6.58 & 7.18 & 6.83
\end{tabular}

Source: own calculations from data provided by the University of Valencia

Possible explanations for the improvement may be due to either a less strict grading system at the host university and/or the student's own maturity. Therefore, it is relevant to check whether the improvement is maintained or not when the students come back to their home university. Figures presented in Table 4 indicate that, although the upgrading is not completely maintained $\left(G P A \_a<G P A \_d\right)$, there is an effect that contributes to slightly increase their GPAs with respect to the ones before joining the host university (GPA_a> $\left.G P A \_b\right)$. These results are consistently analogous for the four clusters of students considered.

Both the figures in Table 4 and the results obtained from the estimation of Eq. 1 confirm the influence of the mobility period on the students' academic performance. To delve further into this issue, we have created the following three variables, which indicate a GPA variation:

- $\quad I \_o u t_{i}=G P A \_d_{i}-G P A \_U V_{i}$ :

- $\quad I \_a b_{i}=G P A \_a_{i}-G P A \_b_{i}$ :

- $\quad I \_a d_{i}=G P A \_a_{i}-G P A \_d_{i}$ :

The variable I_out can be used as a proxy to measure the improvement of the students' grades during their mobility period -question a) in section 1- whereas the other two variables can be used as a proxies to measure the academic improvement after coming back from their mobility period -question $b$ ) in section 1 - with respect to either their previous academic performance at the UV $\left(I \_a b\right)$ or the host university $\left(I \_a d\right)$. In our opinion, $I \_a b$ constitutes the variable that better helps to measure the contribution of the mobility period to the improvement of the academic performance of the student. In turn, I_ad helps to interpret and modulate the results obtained with $I \_a b$, since it checks how permanent the 
mobility benefits are (in case there are any) or if they vanish when students come back to their home university.

Graph 1 shows the histograms of the three aforementioned variables whereas Table 5 shows their descriptive statistics and also the percentage of students who improve their performance (i.e., percentage of cases in which the GPA increment is positive).

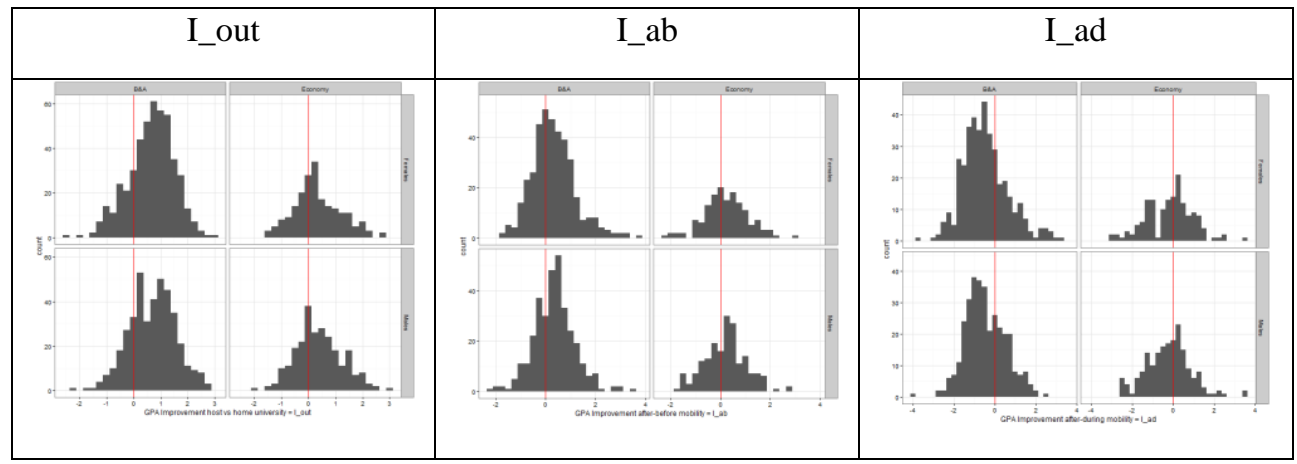

Source: own calculations from data provided by the University of Valencia. Each of the figures has four panels; top panels refer to the female students and left panels refer to the BA students.

Graph 1: Histograms of the variables indicating GPA variation

Table 5: Descriptive statistics for the three endogenous variables

\begin{tabular}{|c|c|c|c|c|c|}
\hline Variable & Mean & Median & St. Dev. & $\begin{array}{c}\text { \% cases the variable } \\
\text { takes positive values }\end{array}$ & $\begin{array}{c}\text { Student's t-test } \\
\text { statistic }\end{array}$ \\
\hline$I \_o u t_{i}$ & 0.57 & 0.59 & 0.86 & $74.57 \%$ & $34.442^{\mathrm{a}}$ \\
\hline$I \_a b_{i}$ & 0.29 & 0.28 & 0.85 & $64.05 \%$ & $7.058^{\mathrm{a}}$ \\
\hline$I \_a d_{i}$ & -0.36 & -0.43 & 1.09 & $35.95 \%$ & $-10.014^{\mathrm{a}}$ \\
\hline
\end{tabular}

Source: own calculations from data provided by the University of Valencia. Note: superscripts $a, b$ and $c$ denote statistical significance at 99.9\%, 99\% and 95\% levels, respectively.

Both Graph 1 and Table 5 seem to suggest that for a typical student, the mobility period contributes to increase her/his GPA but when s/he comes back to her home university, part of the increment disappears. In this sense, the fourth column of Table 5 is especially enlightening: (i) almost $75 \%$ of the students have better marks at the host university than at the UV; (ii) in many cases there is a setback in their grades at the UV when they come back from their mobility period; and (iii), almost two thirds of the students (64.05\%) improve their GPA when only the periods after and before the mobility are considered, using the same grading system at the UV. The latter is the most striking result in our research. 
To check if the variations of the GPAs at the diverse stages are statistically significant a ttest has been used, in which the test statistic follows a Student's t-distribution under the null hypothesis that two sets of data are not significantly different from each other. Table 5 shows that in all cases this null hypothesis is clearly rejected with a significance level of 99.9\% so indicating that the GPAs at different stages are statistically different. Our results are totally in line with Sanz \& Roldan (2005) who show that Socrates/Erasmus students' results obtained during the mobility period are significantly higher than the ones they had previously, and with Meya \& Suntheim (2014) who conclude that a temporary study-related visit abroad significantly improves the final university grade.

\section{Conclusions}

This paper empirically analyses the effect that the mobility period has on the academic performance of university students who enjoy a mobility grant. To do so, using the academic records of each student we compute his/her GPA at three different stages of his/her university studies (before, during and after the mobility period) and compare them. The data employed for the empirical study comes from a large sample of students from the Economics and Business Administration degrees of the Faculty of Economics (University of Valencia) during thirteen academic years (from 2001-02 to 2013-14).

The main result of our study indicates that the mobility period significantly contributes to improve the academic performance of the students. On average, the typical GPA per student during the mobility period is consistently higher than his/her prior GPA at the University of Valencia. This result is valid for all groups of students, regardless of the gender or the degree considered. More importantly, even though the improvement is not totally maintained when the students come back to their home university after the mobility period -it partially vanishes off-, at least there exists an effect that contributes to increase their GPAs with respect to the ones before joining the host university. Therefore, the answer to the two questions pointed out in the introduction (Do the students improve their grades during / after their mobility stay?) is affirmative in both cases. Our results are totally in line with previous literature.

Our findings have clear education policy implications; besides the commonly accepted benefits of mobility programmes at different levels, our research highlights the academic side of the exchanges, stressing the need to maintain the scheme of mobility grants for university students since their academic grades are positively affected by the mobility experience. 


\section{References}

Crossman, J.E., \& Clarke, M. (2010). International experience and graduate employability: stakeholder perceptions on the connection. Higher Education, 59(5), 599-613.

Di Pietro, G. (2013). Do Study Abroad Programs Enhance the Employability of Graduates? Discussion Paper No. 7675, Bonn: Institute for the Study of Labour.

Garbanzo, G. (2007). Factores asociados al rendimiento académico en estudiantes universitarios, una reflexión desde la calidad de la educación superior pública. Educación, 31(1), Universidad de Costa Rica, 43-63.

Juva, E., \& Lesjak, M. (2011). Erasmus Exchange Program: Opportunity for professional growth or sponsored vacations? Journal of Hospitality \& Tourism Education, 23, 23-29.

Maiworm, F., \& Teichler, U. (2002). The Student's Experience, in: U. Teichler (Ed) ERASMUS in the SOCRATES Programme (Bonn, Lemmens), 83-116.

Messer, D., \& Wolter, S.C. (2007). Are Student Exchange Programmes Worth it? Higher Education 54, 647-663.

Meya, J., \& Sutheim, K. (2014). The second dividend of studying abroad: The impact of international student mobility on academic performance. Discussion papers, Center for European Governance and Economic Development Research, No. 215.

Parveen, A., \& Alam, M. (2008). Does Mothers' Education Influence Children's Personality Factors and Academic Achievement? Bulletin of Education and Research, 30(2), 1-6.

Pérez-Vázquez, P., González-Baixauli, C., \& Montañés-Brunet, E. (2014). Do Erasmus Students Get Academic Paybacks from Their Stay Abroad? An Empirical Analysis of Students' Academic Performance. Proceedings of INTED14. 8th International Technology, Education and Development Conference. Valencia (Spain), 2680-2687.

Sanz, I., \& Roldan, I. (2005). Academic Performance of the English Department Students at the University of Granada and its relation with the Socrates/Erasmus Mobility (1997/2000). International Journal of Learning, vol. 12, num. 9, 215-222.

Wiers-Jenssen, J. (2011). Background and Employability of Mobile vs.Non-Mobile Students, Tertiary Education and Management, 17(2), 79-100.

Williams, T. R. (2005). Exploring the Impact of Study Abroad on Students' Intercultural Communication Skills: Adaptability and Sensitivity. Journal of Studies in International Education, 9 (4), 356-371. 